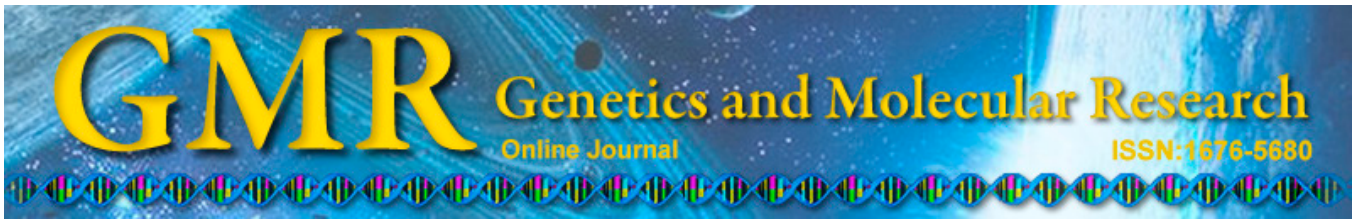

\title{
Interleukin-10 polymorphisms associated with susceptibility to acute myeloid leukemia
}

\author{
C. Fei ${ }^{1}$, X.M. Yao ${ }^{2}$, Y. $\mathrm{Sun}^{3}$, X.Z. Gu ${ }^{2}$, L.Q. Yu ${ }^{2}$ and X. $\mathrm{Lai}^{2}$ \\ ${ }^{1}$ Nephrology Department, First People's Hospital of Yunnan Province, \\ Kunming, Yunnan, China \\ ${ }^{2}$ Haematology Department, First People's Hospital of Yunnan Province, \\ Kunming, China \\ ${ }^{3}$ Molecular Biology Laboratory, First People's Hospital of Yunnan Province, \\ Kunming, China \\ Corresponding author: X. Lai \\ E-mail: laisheen1984@163.com \\ Genet. Mol. Res. 14 (1): 925-930 (2015) \\ Received November 7, 2013 \\ Accepted October 23, 2014 \\ Published February 2, 2015 \\ DOI http://dx.doi.org/10.4238/2015.February.2.15
}

\begin{abstract}
We investigated the association between polymorphisms in interleukin-10 (IL-10) -1082G/A (rs1800896), -819T/C (rs1800871), and $-592 \mathrm{~A} / \mathrm{C}$ (rs1800872) and the risk of acute myeloid leukemia (AML) in a Chinese population. A total of 167 primary AML cases and 328 healthy control subjects were recruited at the First People's Hospital of Yunnan Province between March 2009 and January 2012. The polymorphisms rs1800896, rs1800871, and rs1800872 were genotyped by polymerase chain reaction-restriction fragment length polymorphism. Multivariate regression analyses showed that subjects carrying the rs $1800871 \mathrm{CC}$ genotype and $\mathrm{C}$ allele had a significantly increased risk of AML, with adjusted odds ratios (95\% confidence intervals) of 1.72 (1.01-2.97) and 1.38 (1.04-1.81), respectively. Those carrying the rs $1800872 \mathrm{G}$ allele had a slightly increased risk of AML, with an adjusted odds ratio (95\% confidence interval) of 1.30 (1.011.72). Moreover, genotyping results demonstrated that subjects carrying both the rs $1800871 \mathrm{C}$ allele and rs1800872 $\mathrm{G}$ allele had a moderately
\end{abstract}


increased risk of AML, indicating that the 2 genotypes had a synergistic effect on AML risk (odds ratio $=2.03,95 \%$ confidence interval $=1.24$ 3.15). Our results demonstrated that polymorphisms in rs1800871 and rs1800872 enhance the risk of AML, and these 2 single nucleotide polymorphisms have a synergistic effect on AML risk.

Key words: Acute myeloid leukemia; Interleukin-10; Polymorphism

\section{INTRODUCTION}

Acute leukemia includes acute lymphoblastic leukemia and acute myeloid leukemia (AML) (Mandegary et al., 2011). AML is the most common type of acute leukemia affecting adults (Jiang et al., 2011). The etiology of AML is complicated and not completely understood. Several factors are thought to play an important role in AML development, such as chemical exposure, ionizing radiation, and genetics (Evans and Steward, 1972; Le Beau et al., 1986).

Interleukins (ILs) are a diverse set of small cell signaling protein molecules, or cytokines, that function to alter the immune system in humans (Lippitz, 2013; Tsai et al., 2013). ILs are predominantly produced by antigen-presenting cells, monocytes, macrophages, and endothelial cells, which are involved in the regulation of immune cell responses against infections, as well as governing the inflammation, differentiation, proliferation, and secretion of antibodies for tumor development (Salazar-Onfray et al., 2007; Gounaris et al., 2009). Single nucleotide polymorphisms (SNPs) of ILs may alter their function, thus changing cytokine function and dysregulating their expression (Zhou et al., 2008). The gene encoding IL-10 is located on chromosome 1 (1q31-1q32) and displays a few polymorphisms in the promoter region of the transcriptional start site, including $I L-10-1082 \mathrm{G} / \mathrm{A}$ (rs1800896), -819T/C (rs1800871), and -592A/C (rs1800872). Only one study has indicated that polymorphisms in $I L-10$ were associated with AML (Yao et al., 2013). Therefore, we investigated the association between polymorphisms in $I L-10$-1082G/A (rs1800896), -819T/C (rs1800871), and -592A/C (rs1800872) and the risk of AML in a Chinese population.

\section{MATERIAL AND METHODS}

A total of 182 primary AML cases were recruited from patients who were first diagnosed with AML at the First People's Hospital of Yunnan Province between March 2009 and January 2012. AML diagnosis was determined according to World Health Organization criteria based on an increased number of myeloblasts in the bone marrow or peripheral blood. AML was diagnosed when a 200-cell differential revealed the presence of $20 \%$ or more myeloblasts in a marrow aspirate or in the blood (Vardiman et al., 2002). A total of 167 patients with AML agreed to provide blood sample and undergo investigation, with a participation rate of $91.75 \%$.

Additionally, 328 age-matched control subjects ( \pm 5 years) were recruited from individuals who came to our hospital for a routine health check-up between March 2009 and January 2012. Subjects with a history of cancer, known blood disorders, diabetes, and connective tissue disease were excluded from the study. 


\section{Genotyping analysis}

All study participants were asked to provide $5 \mathrm{~mL}$ venous blood, which was collected in ethylenediaminetetraacetic acid-coated tubes; samples were stored at $-20^{\circ} \mathrm{C}$ until use. Genomic DNA was extracted using the TIANamp blood DNA kit (Tiangen Biotech, Beijing, China) according to manufacturer instructions. Polymerase chain reaction (PCR)-restriction fragment length polymorphism was used to genotype rs1800896, rs 1800871, and rs 1800872 in $I L-10$. Primers and probes of rs 1800896 , rs 1800871 , and rs 1800872 in $I L-10$ were designed using the Sequenom Assay Design 3.1 software (Table 1). PCR started at $94^{\circ} \mathrm{C}$ for $5 \mathrm{~min}$, followed by denaturation at $94^{\circ} \mathrm{C}$ for $45 \mathrm{~s}$, annealing at $62^{\circ} \mathrm{C}$ for $60 \mathrm{~s}$, and extension at $72^{\circ} \mathrm{C}$ for $60 \mathrm{~s}$, with a final extension at $72^{\circ} \mathrm{C}$ for $10 \mathrm{~min}$. Reproducibility was verified by repeat analysis of a randomly chosen subgroup for $10 \%$ of the subjects.

Table 1. Primers and PCR products of rs1800896, rs1800871, and rs 1800872.

\begin{tabular}{llc}
\hline & Primers & PCR products \\
\hline rs1800896 & Forward: 5'-CTACTAAGGCTTCTTTGGGAG-3' & 377 bp \\
& Reverse: 5'-ACTACTAAGGCTTCTTGGGAA-3' & 209 bp \\
rs1800871 & Forward: 5'-TCATTCTATGTGCTGGAGATGG-3' & \\
& Reverse: 5'-TGGGGGAAGTGGGTAAGAGT-3' & $412 \mathrm{bp}$ \\
& Forward: 5'-GGTGAGCACTACCTGACTAGC-3' & \\
\hline
\end{tabular}

\section{Statistical analysis}

All statistical analyses were performed using the SPSS 16.0 software (SPSS Inc., Chicago, IL, USA). Continuous and categorical variables are reported as means \pm standard deviation and $\mathrm{N}(\%)$ of study participants, respectively. Patients and control subjects were compared using the Student $t$-test, while the $\chi^{2}$ test was used to determine whether the genotype distribution of the 3 SNPs were in line with Hardy-Weinberg equilibrium among the controls. The association between polymorphisms in rs1800896, rs1800871, and rs1800872 and risk of AML were assessed using an unconditional multiple logistical regression model with estimated odds ratios (ORs) and 95\% confidence intervals (CIs). All statistical tests were two-sided, and a $\mathrm{P}$ value less than 0.05 was considered to be statistical significant.

\section{RESULTS}

Allele and genotype distributions of rs1800896, rs1800871, and rs1800872 were within the parameters of Hardy-Weinberg equilibrium for the control group, with $\mathrm{P}$ values of $0.38,0.10$, and 0.09 , respectively (Table 2 ). Minor allele frequencies among healthy controls were consistent with those of the Chinese population reported in the National Center for Biotechnology Information dbSNP databases.

Allele frequencies for rs 1800871 were significantly different between AML cases and control subjects $\left(\chi^{2}=4.48, P=0.034\right)$, while the frequencies of rs 1800896 and rs 1800872 were not. Multivariate regression analyses showed that subjects carrying the rs $1800871 \mathrm{CC}$ genotype and $\mathrm{C}$ allele had a significantly increased risk of AML, with adjusted ORs $(95 \% \mathrm{CI})$ of $1.72(1.01-2.97)$ and $1.38(1.04-1.81)$, respectively (Table 3). Moreover, we found that 
those carrying the rs $1800872 \mathrm{G}$ allele had a slightly increased risk of AML, with an adjusted OR $(95 \% \mathrm{CI})$ of $1.30(1.01-1.72)$.

Table 2. Genotype characteristics of the 3 single nucleotide polymorphisms.

\begin{tabular}{lccccc}
\hline & SNP & Alleles & \multicolumn{2}{c}{ MAF } & HWE (P value) in controls \\
\cline { 3 - 5 } & & & Control group & From dbSNP & 0.38 \\
\hline$-1082 \mathrm{G} / \mathrm{A}$ & $\mathrm{rs} 1800896$ & $\mathrm{~A} / \mathrm{C}$ & 0.3115 & 0.3026 & 0.10 \\
$-819 \mathrm{~T} / \mathrm{C}$ & $\mathrm{rs} 1800871$ & $\mathrm{~T} / \mathrm{C}$ & 0.3748 & 0.4086 & 0.09 \\
$-592 \mathrm{~A} / \mathrm{C}$ & $\mathrm{rs} 1800872$ & $\mathrm{~A} / \mathrm{G}$ & 0.398 & 0.4091 & \\
\hline
\end{tabular}

$\mathrm{MAF}=$ minor allele frequencies; HWE $=$ Hardy-Weinberg equilibrium.

Table 3. Association between polymorphisms of $I L-10$ genetic variants and AML.

\begin{tabular}{|c|c|c|c|c|c|c|c|c|c|}
\hline SNPs & & $\begin{array}{c}\text { Cases } \\
(\mathrm{N}=167)\end{array}$ & $\%$ & $\begin{array}{l}\text { Controls } \\
(\mathrm{N}=328)\end{array}$ & $\%$ & Crude OR $(95 \% \mathrm{CI})$ & $P$ value & Adjusted OR $(95 \% \mathrm{CI})^{1}$ & $P$ value \\
\hline \multirow[t]{5}{*}{ rs1800896 } & $\mathrm{AA}$ & 75 & 44.7 & 159 & 48.5 & 1.0 (Ref.) & - & 1.0 (Ref.) & - \\
\hline & $\mathrm{AC}$ & 70 & 42.1 & 134 & 40.7 & $1.11(0.73-1.68)$ & 0.62 & $1.24(0.82-1.80)$ & 0.45 \\
\hline & $\mathrm{CC}$ & 22 & 13.2 & 35 & 10.8 & $1.33(0.69-2.52)$ & 0.35 & $1.45(0.72-2.67)$ & 0.27 \\
\hline & A allele & 220 & 65.75 & 452 & 68.9 & 1.0 (Ref.) & - & 1.0 (Ref.) & - \\
\hline & $\mathrm{C}$ allele & 114 & 34.25 & 204 & 31.2 & $1.15(0.86-1.53)$ & 0.33 & $1.22(0.92-1.62)$ & 0.21 \\
\hline \multirow{5}{*}{ rs1800871 } & TT & 57 & 34.2 & 137 & 41.8 & 1.0 (Ref.) & - & 1.0 (Ref.) & - \\
\hline & $\mathrm{CT}$ & 72 & 43.1 & 137 & 41.8 & $1.26(0.81-1.97)$ & 0.27 & $1.24(0.80-2.02)$ & 0.18 \\
\hline & $\mathrm{CC}$ & 38 & 22.7 & 54 & 16.5 & $1.69(0.97-2.93)$ & 0.04 & $1.72(1.01-2.97)$ & 0.03 \\
\hline & T allele & 186 & 55.75 & 411 & 62.7 & 1.0 (Ref.) & - & 1.0 (Ref.) & - \\
\hline & $\mathrm{C}$ allele & 148 & 44.25 & 245 & 37.3 & $1.33(1.01-1.76)$ & 0.03 & $1.38(1.04-1.81)$ & 0.02 \\
\hline \multirow[t]{5}{*}{ rs 1800872} & AA & 54 & 32.2 & 126 & 38.5 & 1.0 (Ref.) & - & 1.0 (Ref.) & - \\
\hline & $\mathrm{AG}$ & 74 & 44.3 & 142 & 43.4 & $1.22(0.78-1.90)$ & 0.37 & $1.18(0.84-1.65)$ & 0.25 \\
\hline & GG & 39 & 23.5 & 59 & 18.1 & $1.54(0.89-2.66)$ & 0.09 & $1.56(0.95-2.74)$ & 0.07 \\
\hline & A allele & 182 & 54.35 & 394 & 60.2 & 1.0 (Ref.) & - & 1.0 (Ref.) & - \\
\hline & $\mathrm{G}$ allele & 152 & 45.65 & 260 & 39.8 & $1.27(0.96-1.67)$ & 0.08 & $1.30(1.01-1.72)$ & 0.04 \\
\hline
\end{tabular}

${ }^{1}$ Adjusted for gender and age. $\mathrm{OR}=$ odds ratio; $95 \% \mathrm{CI}=95 \%$ confidence interval.

Further analysis was conducted to evaluate the interaction between the rs 1800871 and rs1800872 polymorphisms on the susceptibility to AML (Table 4). Genotyping results demonstrated that subjects carrying both the rs $1800871 \mathrm{C}$ allele and rs $1800872 \mathrm{G}$ allele had a moderately increased risk of AML, indicating that the 2 genotypes have a synergistic effect on AML risk $(\mathrm{OR}=2.03,95 \% \mathrm{CI}=1.24-3.15, \mathrm{P}$ value $=0.001)$.

\section{Table 4. Combination effect of rs1800871 and rs1800872 on AML risk.}

\begin{tabular}{|c|c|c|c|c|c|c|c|c|}
\hline rs $1800871 / \mathrm{rs} 1800872$ & $\begin{array}{c}\text { Cases } \\
(\mathrm{N}=167)\end{array}$ & $\%$ & $\begin{array}{c}\text { Controls } \\
(\mathrm{N}=328)\end{array}$ & $\%$ & Crude OR $(95 \% \mathrm{CI})$ & $P$ value & Adjusted OR $(95 \% \mathrm{CI})^{1}$ & $P$ value \\
\hline $\mathrm{T}$ allele/A allele & 96 & 57.5 & 236 & 72.0 & 1.0 (Ref.) & - & 1.0 (Ref.) & - \\
\hline $\mathrm{T}$ allele/G allele & 90 & 53.9 & 175 & 53.4 & $1.26(0.88-1.82)$ & 0.19 & $1.29(0.92-1.93)$ & 0.14 \\
\hline $\mathrm{C}$ allele/A allele & 86 & 51.5 & 158 & 48.2 & $1.34(0.92-1.94)$ & 0.11 & $1.36(0.93-2.03)$ & 0.13 \\
\hline $\mathrm{C}$ allele/G allele & 62 & 37.1 & 85 & 25.9 & $1.79(1.17-2.74)$ & 0.005 & $1.85(1.23-2.78)$ & 0.001 \\
\hline
\end{tabular}

${ }^{1}$ Adjusted for gender and age. $\mathrm{OR}=$ odds ratio; $95 \% \mathrm{CI}=95 \%$ confidence interval.

\section{DISCUSSION}

IL-10 is an important immunoregulatory cytokine that is produced by activated T cells, monocytes, B cells, and thymocytes. IL-10 plays an important role in stimulating and suppressing the immune response, and functions as an immune response modulator (Helminen 
et al., 1999). Polymorphisms in the promoter region of the $I L-10$ gene may influence tumor development by altering the levels of IL-10 present in the serum or tumor microenvironment. Previous studies reported several polymorphic sites in the $I L-10$ gene promoter region in the transcription start site, including 3 balletic polymorphisms at positions $-1082 \mathrm{~A} / \mathrm{G},-819 \mathrm{C} / \mathrm{T}$, and $-592 \mathrm{~A} / \mathrm{C}$. Previous studies reported that $I L-10$ promoter polymorphisms were associated with AML risk (Gao et al., 2011; Li et al., 2012). In this matched case-control study, we analyzed genetic polymorphisms in the $I L-10$ promoter and the risk of AML. The main finding of our study was that subjects carrying the rs 1800871 CC genotype and C allele and rs 1800872 $\mathrm{G}$ allele showed a significantly increased risk of AML, and that the rs $1800871 \mathrm{C}$ allele and rs $1800872 \mathrm{G}$ allele had a synergistic effect on the risk of AML. However, the rs 1800896 polymorphisms were not associated with AML.

It has been reported that IL-10 regulates the differentiation and proliferation of several immune cells, has both tumor-promoting and tumor-inhibiting properties, and thus plays a role in tumor development and metastasis (Couper et al., 2008). Polymorphisms in $I L-10$ can alter the function of this cytokine and may be associated with disease development. Previous studies indicated that $I L-10$ polymorphisms are associated with various cancers such as gastric cancer, lung cancer, head and neck squamous cell carcinoma, oral cancer, cervical cancer, and prostate cancer (Howell and Rose-Zerilli, 2007; Tsai et al., 2013; Pan et al., 2013; Sun et al., 2013). Tsai et al. (2013) reported that individuals carrying the rs 1800896 AG and GG genotypes had 1.91- and 3.26-fold higher risk of developing nasopharyngeal cancer, and found no significant association between the rs1800871 and rs 1800872 polymorphisms and nasopharyngeal cancer risk. Another study conducted in China indicated that rs 1800872 was associated with the overall risk of non-cardiac gastric cancer (Pan et al., 2013). For AML, only 2 studies reported an association between the rs 1800871 and rs 1800872 gene polymorphisms and risk of AML (Yao et al., 2013; Chen et al., 2013); these studies showed that polymorphisms in rs1800871 and rs 1800872 may be associated with increased risk of AML, and were correlated with $I L-10$ mRNA expression in AML patients. Similarly, we also found an association between rs1800871 and rs1800872 genetic variations and AML risk.

Patients carrying both the rs $1800871 \mathrm{C}$ allele and rs $1800872 \mathrm{G}$ allele had a moderately increased risk of AML. The 2 SNPs had a synergistic effect on the risk of AML. Two previous studies indicated that polymorphisms in rs1800871 and rs 1800872 had a significant effect on AML risk (Yao et al., 2013; Chen et al., 2013), but these studies did not explore the combination effect on cancer risk. Studies including larger sample sizes are needed to confirm the role of the rs1800871 and rs1800872 genetic variations on AML risk.

In conclusion, we found that polymorphisms in rs1800871 and rs1800872 enhanced the risk of AML, and these 2 SNPs had a synergistic effect on AML risk. Our results suggested that rs1800871 and rs 1800872 may be susceptibility genes for AML, which provides important clues for future studies for early detection of AML. Further large-scale studies with large sample sizes from different ethnic populations are required to confirm our results.

\section{ACKNOWLEDGMENTS}

Research supported by the Natural Science Foundation of Yunnan, China (NSFYC; \#2012FB203) and the Health Science Foundation of Yunnan, China (\#2012WS0064). 


\section{REFERENCES}

Chen JY, Zili F, Hai BC, Ying L, et al. (2013). IL-10 promoter polymorphisms affect IL-10 production and associate with susceptibility to acute myeloid leukemia. Pharmazie 68: 201-206.

Couper KN, Blount DG and Riley EM (2008). IL-10: the master regulator of immunity to infection. J. Immunol. 180: 5771-5777.

Evans DI and Steward JK (1972). Down's syndrome and leukaemia. Lancet 2: 1322.

Gao Q, Zhang S, Wu L, Jia M, et al. (2011). Association of IL-10-1082 and IL-10-592 polymorphisms with chronic hepatitis B and/or hepatitis C virus infection among plasma donors in a rural area of Hebei Province, China. Wei Sheng Yan Jiu 40: 709-713.

Gounaris E, Blatner NR, Dennis K, Magnusson F, et al. (2009). T-regulatory cells shift from a protective anti-inflammatory to a cancer-promoting proinflammatory phenotype in polyposis. Cancer Res. 69: 5490-5497.

Helminen M, Lahdenpohja N and Hurme M (1999). Polymorphism of the interleukin-10 gene is associated with susceptibility to Epstein-Barr virus infection. J. Infect. Dis. 180: 496-499.

Howell WM and Rose-Zerilli MJ (2007). Cytokine gene polymorphisms, cancer susceptibility, and prognosis. J. Nutr. 137: S194-S199.

Jiang L, Zhou P, Sun A, Zheng J, et al. (2011). Functional variant (21304T.G) in the MKK4 promoter is associated with decreased risk of acute myeloid leukemia in a southern Chinese population. Cancer Sci. 102: 1462-1468.

Le Beau MM, Albain KS, Larson RA, Vardiman JW, et al. (1986). Clinical and cytogenetic correlations in 63 patients with therapy-related myelodysplastic syndromes and acute nonlymphocytic leukemia: further evidence for characteristic abnormalities of chromosomes Nos. 5 and 7. J. Clin. Oncol. 4: 325-345.

Li QY, Guo ZZ, Liang J, Zhang W, et al. (2012). Interleukin-10 genotype correlated to deficiency syndrome in hepatitis B cirrhosis. Evid. Based Complement. Alternat. Med. 298925.

Lippitz BE (2013). Cytokine patterns in patients with cancer: a systematic review. Lancet Oncol. 14: e218-e228.

Mandegary A, Rostami S, Alimoghaddam K, Ghavamzadeh A, et al. (2011). Gluthatione-S-transferase T1-null genotype predisposes adults to acute promyelocytic leukemia; a case-control study. Asian Pac. J. Cancer Prev. 12: 1279-1282.

Pan XF, Yang SJ, Loh M, Xie Y, et al. (2013). Interleukin-10 gene promoter polymorphisms and risk of gastric cancer in a Chinese population: single nucleotide and haplotype analyses. Asian Pac. J. Cancer Prev. 14: 2577-2582.

Salazar-Onfray F, López MN and Mendoza-Naranjo A (2007). Paradoxical effects of cytokines in tumor immune surveillance and tumor immune escape. Cytokine Growth Factor Rev. 18: 171-182.

Sun JM, Li Q, Gu HY, Chen YJ, et al. (2013). Interleukin 10 rs1800872 T\&gt;G polymorphism was associated with an increased risk of esophageal cancer in a Chinese population. Asian Pac. J. Cancer Prev. 14: 3443-3447.

Tsai CW, Tsai MH, Shih LC, Chang WS, et al. (2013). Association of interleukin-10 (IL10) promoter genotypes with nasopharyngeal carcinoma risk in Taiwan. Anticancer Res. 33: 3391-3396.

Vardiman JW, Harris NL and Brunning RD (2002). The World Health Organization (WHO) classification of the myeloid neoplasms. Blood 100: 2292-2302.

Yao CJ, Du W, Chen HB, Xiao S, et al. (2013). Associations of IL-10 gene polymorphisms with acute myeloid leukemia in Hunan, China. Asian Pac. J. Cancer Prev. 14: 2439-2442.

Zhou Y, Li N, Zhuang W, Liu GJ, et al. (2008). Interleukin-10 -1082 promoter polymorphism associated with gastric cancer among Asians. Eur. J. Cancer 44: 2648-2654. 